\section{BM Paediatrics Open}

\title{
Carbon dioxide rebreathing induced by crib bumpers and mesh liners using an infant manikin
}

\author{
Matthew R Maltese, ${ }^{\circ 1,2}$ Michael Leshner ${ }^{3}$
}

To cite: Maltese MR, Leshner M. Carbon dioxide rebreathing induced by crib bumpers and mesh liners using an infant manikin. BMJ Paediatrics Open 2019;3:e000374. doi:10.1136/ bmjpo-2018-000374

- Additional material is published online only. To view please visit the journal online (http://dx.doi.org/10.1136/ bmjpo-2018-000374)

Received 21 September 2018 Revised 15 January 2019 Accepted 21 January 2019

\section{Check for updates}

(C) Author(s) (or their employer(s)) 2019. Re-use permitted under CC BY-NC. No commercial re-use. See rights and permissions. Published by BMJ.

${ }^{1}$ Department of Anesthesiology and Critical Care, The Children's Hospital of Philadelphia, Philadelphia, Pennsylvania, USA ${ }^{2}$ Perelman School of Medicine, The University of Pennsylvania, Philadelphia, Pennsylvania, USA ${ }^{3}$ Leshner and Associates, Inc, Elkton, Maryland, USA

Correspondence to Dr Matthew R Maltese; maltese@seas.upenn.edu

\section{ABSTRACT}

Objectives Quantify impaired respiration in currently marketed crib bumpers (CBS), mesh liners (MLs) and alternative products (ALTs) used to attenuate the interaction between the baby and the crib sides and elucidate the relationship between impaired respiration and permeability. Methods We experimentally quantified carbon dioxide rebreathing $\left(\mathrm{CO}_{2} \mathrm{RB}\right)$ via an infant manikin and air permeability via previously published test protocols, in commercially available CBs, MLs and ALTs.

Results Differences in $\mathrm{CO}_{2} \mathrm{RB}$ in $\mathrm{ML}$ (median $[\mathrm{m}]=8.2 \%$, 25th percentile $[\mathrm{P} 25]=6.8,75$ th percentile $[\mathrm{P} 75]=8.6)$, ALT $(m=10.5 \%, P 25=9.8, P 75=10.7)$ and $C B(m=11.6 \%$, $P 25=10.2, P 75=14.3)$ were significant $(p<0.0001)$. For comparison, manikin tests with a pacifier yielded $\mathrm{CO}_{2} \mathrm{RB}$ of $5.6 \%-5.9 \%$, blanket draped over the face/torso yielded $\mathrm{CO}_{2} \mathrm{RB}$ of $7.7 \%-8.6 \%$ and stuffed animal in various positions yielded $\mathrm{CO}_{2} \mathrm{RB}$ from $6.1 \%$ to $16.1 \%$. Differences in permeability between $\mathrm{ML}(\mathrm{m}=529.5$ cubic feet per minute [CFM], P25=460, P75=747.5), ALT ( $\mathrm{m}=29.0 \mathrm{CFM}$, $\mathrm{P} 25=27.7, \mathrm{P} 75=37.7)$ and $\mathrm{CB}(\mathrm{m}=46.6 \mathrm{CFM}, \mathrm{P} 25=30.1$, $P 75=58.7)$ groups were significant $(p<0.0001) . \mathrm{CO}_{2} \mathrm{RB}$ was poorly correlated with air permeability ( $\max R^{2}=0.36$ ). In a subset of tests, $\mathrm{CB} \mathrm{CO}_{2} \mathrm{RB}$ increased by $50 \%-80 \%$ with increasing penetration force, whereas the $\mathrm{ML} \mathrm{CO}_{2} \mathrm{RB}$ was nominally unchanged.

Conclusions Government agencies and standards organisations are presently considering regulation of bedding including CBs. As paediatricians are consulted in the development of such regulations, our findings that permeability by itself was a poor predictor of $\mathrm{CO}_{2} \mathrm{RB}$ should be considered.

\section{INTRODUCTION}

The environmental conditions that lead to sudden infant death syndrome (SIDS)/sudden unexpected infant death (SUID) during sleep vary, including prone sleeping, mattress firmness, crib-sharing, soft objects and loose bedding in the sleep area, smoke exposure and alcohol and illicit drug use of the mother. ${ }^{1}$ Crib bumpers (CBs) have been implicated in 48 deaths between 1985 and 2012, including 23 deaths between 2006 and 2012. ${ }^{2}$ Twenty-five of the 48 cases were found to have the 'bumper alone' as the cause of death, including 13 deaths from infants wedged between a bumper

\section{What is already known on this topic?}

- Bedding, pillows, bumpers and toys have been identified as suffocation risks to children in cribs. The tendency of crib mattresses and mattress covers to induce carbon dioxide $\left(\mathrm{CO}_{2}\right)$ rebreathing has been characterised experimentally in the literature.

- The firmness of the mattress and the ability of the mattress to form a seal around the baby's face as important factors in generating $\mathrm{CO}_{2}$ rebreathing.

\section{What this study hopes to add?}

This study characterises $\mathrm{CO}_{2}$ rebreathing in crib bumpers, mesh liners and other products used to mitigate the crib-to-baby interaction. Product permeability, which has been proposed as a regulatory metric, is not an adequate predictor of $\mathrm{CO}_{2}$ rebreathing.

- The seal and penetration force are important factors as found in mattresses and other bedding materials by previous authors.

and crib mattress and 12 deaths with the infant's face against a bumper without wedging, with all cited as impeding respiration. This impaired respiration associated with CBs is the focus of this report.

Our overarching goal is to examine the environmental and design factors that lead to impaired respiration in products that are used to mitigate harmful interactions between the side of the crib and the infant, and CBs are one such product. In addition, it has been suggested that mesh liners (ML) may mitigate some of the problems found with traditional CBs, as such MLs have been cited as 'breathable and thin'. ${ }^{2}$ Thus, the purpose of this study was to quantify impaired respiration in currently marketed liners, bumpers and alternative (ALT) products and elucidate the relationship between impaired respiration and permeability of the sample. 


\section{METHODS}

No patients were involved in this study. All products were purchased from consumer retail outlets. By material and construction, we categorised each product into one of three categories: (1) MLs were $4 \mathrm{~mm}$ thick or less and were constructed of mesh fabric (1-2 mm openings) and an open fibre scrim, (2) ALT products had two exterior mesh fabric layers more than $4 \mathrm{~mm}$ in total thickness and may have sometimes included a fill of either padding or additional mesh sandwiched between them and (3) CBs consisted of a padded fill material, of thickness ranging from 10 to $55 \mathrm{~mm}$, sandwiched between two exterior non-mesh fabric layers (figure 1).

\section{Carbon dioxide rebreathing $\left(\mathrm{CO}_{2} \mathrm{RB}\right)$ Studies}

Consistent with studies used to examine impaired respiration in infants during sleep, ${ }^{3-10}$ we used $\mathrm{CO}_{2} \mathrm{RB}$ as the metric for quantifying impaired respiration.

$\mathrm{CO}_{2} \mathrm{RB}$ was assessed via an anthropomorphic rebreathing surrogate (ARS). ${ }^{3}{ }^{3}$ The ARS makes use of a mechanical 'lung' of $120 \mathrm{~mL}$ total volume, actuated at a frequency of 45 breaths per minute and $35 \mathrm{~mL}$ tidal volume. The volume of the tubing connecting the lung to the manikin's nose is similar to the infant trachea with a resistance to airflow of $40 \mathrm{~cm} \mathrm{H}_{2} \mathrm{O} / \mathrm{L} / \mathrm{s}$.

As the manikin breathes in and out of its nose, carbon dioxide is metered into the lung to simulate $\mathrm{CO}_{2}$ produced by metabolism. Interactions between the manikin's face and external materials causes a change in the $\mathrm{CO}_{2}$ concentration in the lung, which is measured by withdrawing a very small sample and measuring the $\mathrm{CO}_{2}$ concentration (Fuji Electric Non-Dispersive Infrared Gas Analyzer, Type ZRF). Rotameters ensured constant flow rates (figure 2).

ARS postures were developed from real-world infant death and near death cases, ${ }^{211}$ where the overarching observation was that the face was up against the CB with or without another object applying force to the infant. Given that our goal was to evaluate the $\mathrm{CO}_{2} \mathrm{RB}$ that is affected by the material and structural characteristics of the sample, and not the mattress or other bedding, we focused our study on the scenario where the infant lying on its right or left side with their coronal plane parallel to the sample and the manikin face against the sample. Discussed later, we also examined the possibility of increased penetration force caused by an object pressing the face into the sample.

For a repeatable test setup, we changed the orientation of the crib to take advantage of gravity to apply the forces to the ARS body. This was accomplished by turning the test apparatus $90^{\circ}$ on its side with the manikin face down on the sample. In order to prove out this approach, we conducted several tests with different samples with the crib in the normal position, and then repeated those same tests with the crib side rotated $90^{\circ}$. Using $\mathrm{p}<0.01$ as the level of significance, none of the tested cases achieved a statistically significant difference (sample 3 : $\mathrm{p}=0.03$, sample 10: $\mathrm{p}=0.89$, sample 13: $\mathrm{p}=0.72$, sample 15 :
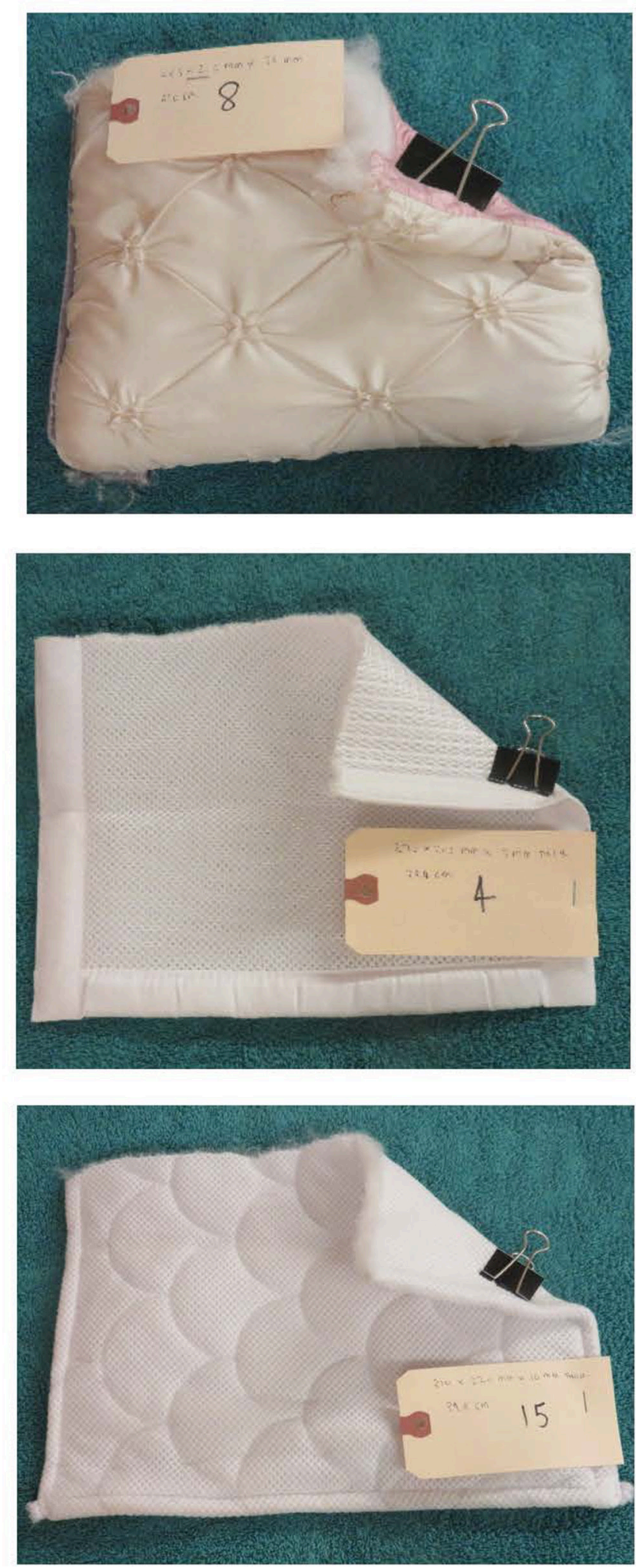

Figure 1 Exemplar products tested: crib bumper (top), mesh liner (middle) and alternative (bottom).

$\mathrm{p}=0.77$ ) between the horizontal and vertical positions (online supplementary figure 1). The percent change in $\mathrm{CO}_{2} \mathrm{RB}$ between the horizontal and vertical crib side positions was $2.41 \%$ across all samples. An appreciation for the effect size can be gained from online supplementary 


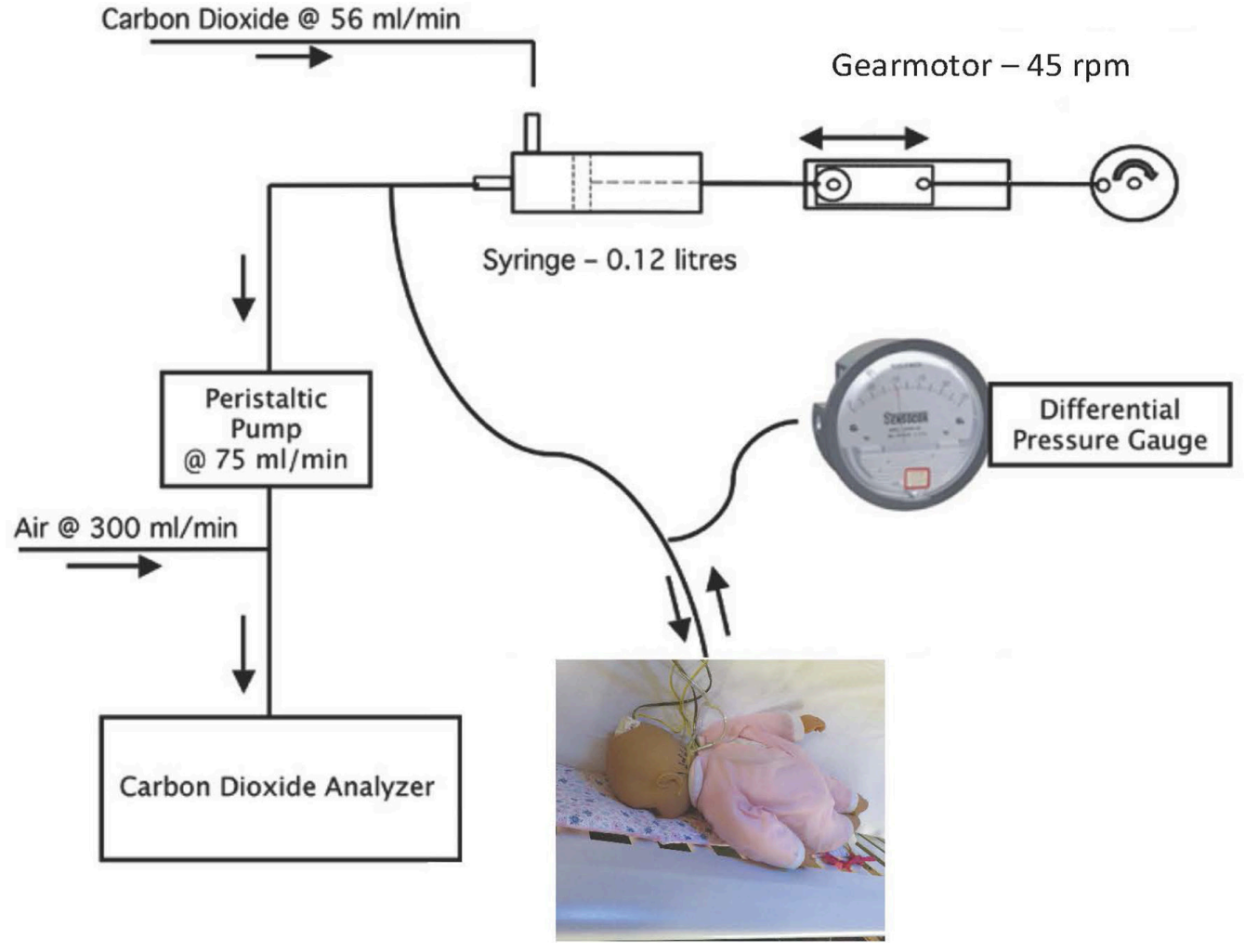

Figure 2 Anthropomorphic rebreathing surrogate (ARS) used in all testing.

figure 1 (available online). Thus, we conducted all experiments with the crib in the horizontal position.

ARS head mass was $2 \mathrm{~kg}$, which is in the range of a 1 to 6 month old. ${ }^{12}{ }^{13}$ We recognise that $2 \mathrm{~kg}$ is on the higher end of the range of the head masses, but this simulates the potential worst case scenario where exogenous forces (wedging, crib-sharing partner or other objects) push the face into the sample. We used a slatted crib with flat slats $40 \mathrm{~mm}$ wide and a $56 \mathrm{~mm}$ gap between edges of adjacent slats; in all tests, we placed the tip of the nose of ARS centred in the gap between the slats.

For each sample, a baseline measurement was taken with the ARS free-breathing and in the centre of the crib away from the sample. Then, the baby was placed prone on the sample, and the manikin remained in this position until the $\mathrm{CO}_{2} \mathrm{RB}$ reached a stable value, after which the $\mathrm{CO}_{2} \mathrm{RB}$ measurement was recorded and the manikin returned to the free-breathing position in the centre of the crib. After the $\mathrm{CO}_{2} \mathrm{RB}$ returned to baseline conditions, the experiment was repeated an additional two times for a total of three measurements per sample. The time between measurements was 2-3 min.

For comparison with the ML, ALT and CB samples, we tested several typical conditions found in unattended sleeping children that have been previously studied in vivo or with an ARS, ${ }^{14} 15$ as well as discovered in retrospective death case studies. ${ }^{16}{ }^{17}$ The first was an infant put to bed supine in the centre of the crib with a pacifier in their mouth. The second was the condition where a receiving blanket, which could become unwrapped from a swaddled baby placed to bed, was draped over the entire face and torso (online supplementary figure 2). In addition to these aforementioned conditions that are plausible when compliant with the safe sleeping recommendations, ${ }^{1}$ we also tested the condition where a stuffed animal was placed in the crib with the child, which would be considered unsafe by the safe sleeping recommendations (online supplementary figure 3). It is important to note that blankets and stuffed animals have been associated with infant death cases. ${ }^{18}$

\section{Permeability studies}

In addition to $\mathrm{CO}_{2} \mathrm{RB}$ testing with the ARS, each sample was subjected to an air permeability test ${ }^{19}$ that measured the volumetric flow rate of air passing perpendicularly through a known area under a prescribed air pressure differential between the two surfaces of a material. In the context of crib bedding, the air permeability test quantifies the resistance of a material to allow the baby to breathe the air on the contralateral side of the material. Each product was tested 10 times.

\section{Data analysis}

Kruskal-Wallis equality-of-populations rank test was used to compare $\mathrm{CO}_{2} \mathrm{RB}$ and permeability results across the three product categories. Across all samples, the relationship between median $\mathrm{CO}_{2} \mathrm{RB}$ and median permeability was quantified via exponential, linear, logarithmic, polynomial and power regression models. All models were built by least squares methods, and permeability was the independent variable, while the $\mathrm{CO}_{2} \mathrm{RB}$ was the dependent variable (table 1 ). 
Table 1 The mathematical model formula and coefficient of determination for all models used to evaluate the relationship between permeability $(x)$ and $\mathrm{CO}_{2} \mathrm{RB}(\mathrm{y})$

\begin{tabular}{ll}
\hline Model & $\mathbf{R}^{2}$ \\
\hline$y=a x+k$ & 0.28 \\
$y=a x^{2}+b x+k$ & 0.28 \\
$y=a x^{3}+b x^{2}+c x+k$ & 0.31 \\
$y=a x^{4}+b x^{3}+c x^{2}+d x+k$ & 0.36 \\
$y=z \ln (x)+k$ & 0.16 \\
$y=a e^{x}$ & 0.36 \\
$y=a x^{b}$ & 0.20
\end{tabular}

$\mathrm{CO}_{2} \mathrm{RB}$, carbon dioxide rebreathing.

To examine the effect of penetration force into the sample on $\mathrm{CO}_{2} \mathrm{RB}$, we evaluated $\mathrm{CO}_{2} \mathrm{RB}$ on a subset of samples with variation on the force that the head places on the sample. The manikin was placed prone on the sample (online supplementary figure 4). Then, 200 $\mathrm{g}$ of steel shot was added to the manikin head through a hole in the occiput, which increased the force applied by the face to the sample. Then, $\mathrm{CO}_{2} \mathrm{RB}$ measurements were made. Additional steel shot was added to head in $200 \mathrm{~g}$ increments for a total added mass of up to $2000 \mathrm{~g}$, with $\mathrm{CO}_{2} \mathrm{RB}$ measurements at each $200 \mathrm{~g}$ increment.

\section{RESULTS}

$\mathrm{CO}_{2} \mathrm{RB}$ Studies

Eighteen products were tested including 5 MLs, 3 ALTs and $10 \mathrm{CBs}$. Differences in $\mathrm{CO}_{2} \mathrm{RB}$ in $\mathrm{ML}$ (median $[\mathrm{m}]=8.2 \%$, 25th percentile $[\mathrm{P} 25]=6.8,75$ th percentile $[\mathrm{P} 75]=8.6)$, ALT $(\mathrm{m}=10.5 \%, \mathrm{P} 25=9.8, \mathrm{P} 75=10.7)$ and $\mathrm{CB}$ $(\mathrm{m}=11.6 \%, \mathrm{P} 25=10.2, \mathrm{P} 75=14.3)$ were statistically significant $(\mathrm{p}<0.0001)$. Ranges of $\mathrm{CO}_{2} \mathrm{RB}$ overlapped between product categories (figure 3 , top). $\mathrm{CO}_{2} \mathrm{RB}$ values vary widely in CB products, compared with ML and ALT products (figure 3, top). The supine infant centred in the crib with a pacifier in its mouth yielded $\mathrm{CO}_{2} \mathrm{RB}$ measurements of $5.6 \%, 5.85 \%, 5.8 \%$ and $5.55 \%$, and the condition with the receiving blanket draped over the entire face and torso yielded $\mathrm{CO}_{2} \mathrm{RB}$ values of $7.7 \%, 7.7 \%$ and $8.55 \%$. The stuffed animal yielded the following results: when positioned on the nose of the infant $\mathrm{CO}_{\mathrm{g}} \mathrm{RB}$ was $7.4 \%, 6.4 \%$ and $6.55 \%$; proximal to the face $\mathrm{CO}_{2}^{2} \mathrm{RB}$ was $6.1 \%$ and $6.2 \%$, and on the face $\mathrm{CO}_{2} \mathrm{RB}$ was $11.65 \%$, $8.55 \%$ and $16.1 \%$.

\section{Permeability studies}

Fifteen of the 18 products tested for $\mathrm{CO}_{2} \mathrm{RB}$ were available at the time of air permeability testing: four MLs, three ALTs and eight CBs. Differences in permeability between ML $(\mathrm{m}=529.5$ cubic feet per minute [CFM], $\mathrm{P} 25=460, \mathrm{P} 75=747.5)$, ALT $(\mathrm{m}=29.0 \quad \mathrm{CFM}, \mathrm{P} 25=27.7$, $\mathrm{P} 75=37.7)$ and $\mathrm{CB}(\mathrm{m}=46.6 \mathrm{CFM}, \mathrm{P} 25=30.1, \mathrm{P} 75=58.7)$ groups achieved statistical significance $(\mathrm{p}<0.0001)$.
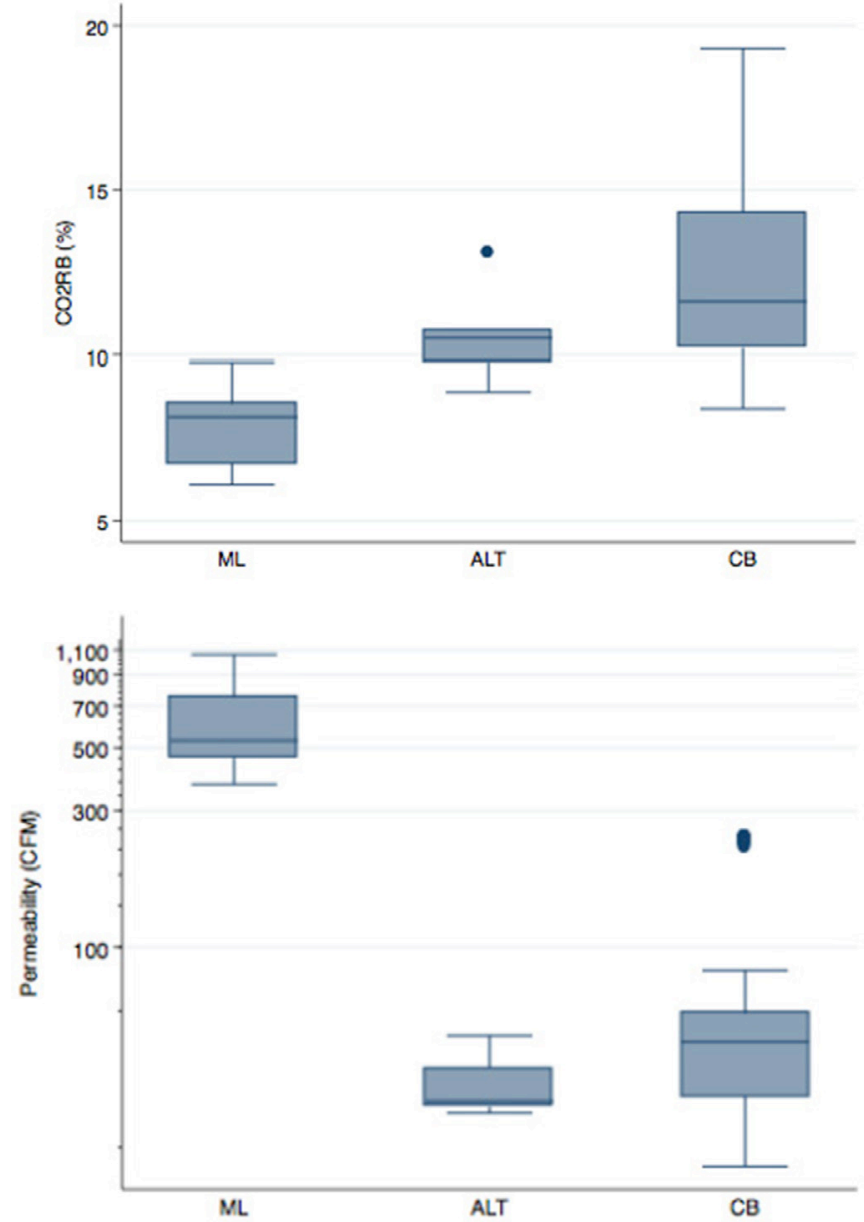

Figure $3 \mathrm{CO}_{2} \mathrm{RB}$ (top) and permeability (bottom) results for mesh liners (ML), alternative products (ALTs) and crib bumpers (CBs). $\mathrm{CO}_{2} \mathrm{RB}$, carbon dioxide rebreathing.

Ranges of permeability did not overlap between product categories (figure 3, bottom).

$\mathrm{CO}_{2} \mathrm{RB}$ was poorly correlated with air permeability (figure 4). Data were fit to exponential, linear, logarithmic, polynomial and power regression models, and none produced a coefficient of determination $\left(\mathrm{R}^{2}\right)$ greater than 0.36 (table 1 ).

Three products (one ML and two CBs) were tested with incrementally increasing penetration force (figure 5). Both CBs showed a higher initial (no weight added to head) $\mathrm{CO}_{2} \mathrm{RB}$ than the MLs, consistent with findings described above. Of note, the $\mathrm{CB} \mathrm{CO}_{2} \mathrm{RB}$ increased by $50 \%-80 \%$ with increasing weight, whereas the ML $\mathrm{CO}_{2} \mathrm{RB}$ was nominally unchanged across the range of weight added to the head.

The raw data from figures 3 and 4 have been supplied in the online supplementary material.

\section{DISCUSSION}

Filiano and Kinney ${ }^{20}$ have posited a 'Triple Risk Model' where three conditions are necessary to result in SIDS-a critical developmental period, a vulnerable infant and an exogenous stressor. This model posits that 'infants who 


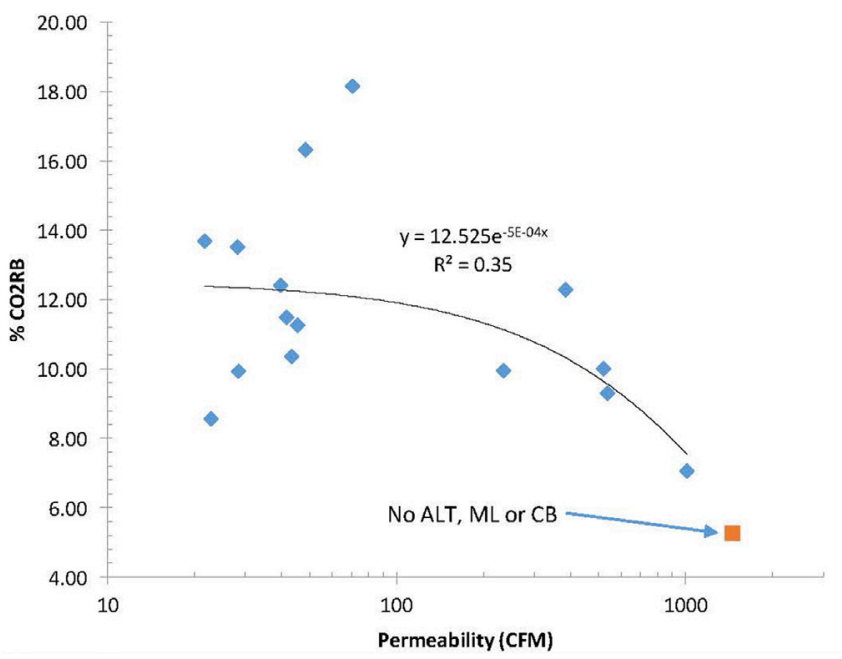

Figure $4 \mathrm{CO}_{2} \mathrm{RB}$ versus permeability for all products tested with both measures $(n=15)$. 'No ALT, ML or CB' case shown for reference purposes, showing $\mathrm{CO}_{2}$ concentrations and volumetric flow rates of test apparatuses without a test sample. Exponential regression model shown. ALT, alternative; $\mathrm{CB}$, crib bumper; $\mathrm{CO}_{2} \mathrm{RB}$, carbon dioxide rebreathing; ML, mesh liners.

eventually die of SIDS may appear normal clinically, but their vulnerability lies latent until they enter the critical development period between 1 and 6 postnatal months and are subject to an exogenous stressor which overwhelms already compromised cardioventilatory or other homeostatic controls'. The Triple Risk Model remains as a foundational paradigm in the analysis of infant death cases. $^{21}$

One essential element of the Triple Risk Model is the exogenous stressor. In the context of deaths attributed to bedding including $\mathrm{CBs}$, the exogenous stressor is impaired respiration that arises when the infant's mouth and nose are pressed against a bedding material. It has been shown that some infants exposed to such conditions attempt self-rescue by increasing their tidal volume. ${ }^{9}$

The ML, ALT and CB product materials are mediums that store gas and thus exhaled $\mathrm{CO}_{2}$ is stored within the product, leading to the potential for $\mathrm{CO}_{2} \mathrm{RB}$. Though the stored $\mathrm{CO}_{2}$ dissipates from the product to the atmosphere in accordance with Fick's laws of diffusion and the permeability of the material, the rate of dissipation may be low enough that by the time the next breath begins, the baby inhales the gas stored in the sample from the previous breath cycle. Similar to studies of other bedding products, ${ }^{3} 4622$ we hypothesised that $\mathrm{CO}_{2} \mathrm{RB}$ would be influenced by the tendency for the $\mathrm{CO}_{2}$ to become retained within the fibres of the ML, ALT or CB, which in turn is likely related to the gas permeability of the sample.

We empirically quantified $\mathrm{CO}_{2} \mathrm{RB}$ and permeability in ML, CBs or ALT products. We found that MLs had the lowest $\mathrm{CO}_{2} \mathrm{RB}$ and the highest permeability, compared with ALT and CB products. In addition, we found that permeability by itself was a poor predictor of $\mathrm{CO}_{2} \mathrm{RB}$ overall, though permeability did distinguish between

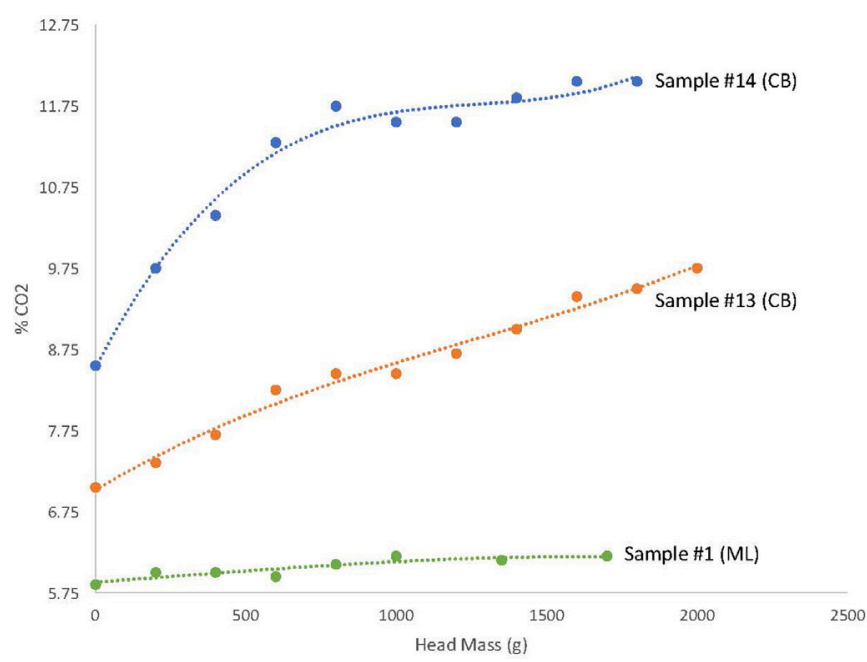

Figure $5 \mathrm{CO}_{2} \mathrm{RB}$ with manikin prone on $\mathrm{ML}$ or $\mathrm{CB}$, with varying mass added to the head. $\mathrm{CB}$, crib bumper; $\mathrm{CO}_{2} \mathrm{RB}$, carbon dioxide rebreathing; $\mathrm{ML}$, mesh liner.

MLs and ALTs or CBs. Of note, the $\mathrm{CO}_{2} \mathrm{RB}$ was higher in CBs than ALTs, but the permeability of ALTs was higher than CBs. This inverse relationship between $\mathrm{CO}_{2} \mathrm{RB}$ and permeability in CBs and ALTs, likely fueled the poor correlation between $\mathrm{CO}_{2} \mathrm{RB}$ and permeability shown in figure 4 .

Patel and colleagues ${ }^{9}$ studied the inspired $\mathrm{CO}_{2}$ in infants face-down on bedding and demonstrated that ${ }^{2} \mathrm{CO}_{2}$ rebreathing was predicated on the seal made between the face and the bedding material. Thus, as in the case of bedding, we posit that $\mathrm{CO}_{2} \mathrm{RB}$ in MLs, ALTs and CBs is predicated on both the permeability of material, which dictates the rate at which gas diffuses out of the sample, and the seal that the nares make with the sample, which dictates how much of the exhaled gas is directed into the sample. To be clear, by a 'seal' we mean that the skin of the face surrounding the nares makes nearly continuous contact circumferentially around the nares, such that exhaled gas is primarily directed into the sample and not into the atmosphere. During our testing, we noted that wrinkles or valleys sometimes developed in the sample when the baby was placed face down in the sample, and these wrinkles and valleys created air channels that break the aforementioned seal. We anecdotally observed that wrinkles and valleys sometimes occur more frequently in the thicker samples, likely leading to the variability observed in the $\mathrm{CO}_{2} \mathrm{RB}$ of the $\mathrm{CBs}$ as compared with the ALTs and MLs (figure 3).

To examine this further, we tested $\mathrm{CO}_{2} \mathrm{RB}$ with the manikin face down on a sample with varied weight added to the head to modulate penetration force. The CB $\mathrm{CO}_{2} \mathrm{RB}$ increased by $50 \%-80 \%$ with increasing penetration force, whereas the $\mathrm{ML} \mathrm{CO}_{2} \mathrm{RB}$ was nominally unchanged across the range of penetration force. This latter point suggests that the ML has an invariant and thus more predictable performance across a wide range of environmental force conditions. This has implications for crib-sharing situations, which are discouraged 
by the 2016 American Academy of Pediatrics guidelines ${ }^{1}$ but which occur in the field, and sleeping situations with other objects or bedding. That is, the ML shows a stable $\mathrm{CO}_{2} \mathrm{RB}$ that is independent of applied force, and thus should a baby's head be pressed against the ML by a crib-sharing partner or other object the $\mathrm{CO}_{2} \mathrm{RB}$ will remain at unweighted head levels (figure 5). In contrast, $\mathrm{CB} \mathrm{CO}_{2} \mathrm{RB}$ increases with applied force, indicating that increased exogenous force to the back of the head (such as in crib sharing or wedging ${ }^{2}$ ) may lead to unpredictable and elevated $\mathrm{CO}_{2} \mathrm{RB}$ levels in CBs.

Approximately 1 in 7 infant deaths and 1 in 3 postneonatal deaths in the USA were attributed to SUID in $2010 .{ }^{23}$ SUID is defined as any sudden and unexpected death, whether explained or unexplained occurring during infancy. Following investigation, SUID can be attributed to a cause of death (suffocation, asphyxia, entrapment, infection and so on). SIDS is a subcategory of SUID and is the assigned cause of death when, after a thorough investigation, a cause of death cannot be explained. ${ }^{24}$ The practice of investigation, autopsy and the assigning of causes of death on the death certificate vary greatly by geographic region. Thus, the national data in the USA lacks consistency in the definitions of infant death aetiologies. ${ }^{2}$ With the aforementioned limitations, we can still gain some information from national cause of death data. In 2015, SUID deaths were attributed to the following aetiologies: SIDS $(43 \%)$, accidental suffocation and strangulation in bed $(25 \%)$ and unknown $(32 \%) .^{25}$

Scheers $e t a l^{2}$ queried the Consumer Product Safety Commission databases for CB-related deaths and injuries between 1985 and 2012. In that study, 32 deaths were attributed to the $\mathrm{CB}$ alone. These included the following scenarios: 13 cases where 'infants wedged between a bumper and crib mattress', 12 cases where the 'infant's face against a bumper without wedging', 3 cases where the 'infant's arm caught between the bumper and the mattress/side rails found with their faces pressed against a bumper'. In addition, four cases of deaths were not related to $\mathrm{CO}_{2} \mathrm{RB}$ (fall and strangulation).

In that same study, 16 deaths were attributed to the $\mathrm{CB}$ and another object. These include nine deaths from 'wedging between a pillow and a bumper', five deaths from 'infants wedged between a bumper and a recliner', one death in a 'crib depression where the bumper prevented the infant from turning her face to the side to breathe,' and one death from 'wedging between a co-sleeping twin and a bumper'.

In addition, the authors reported 11 apparent life-threatening events attributed to the CB: two infants 'found with their faces pressed into bumper', one case of an infant 'wedged between a bumper and mattress', one case of an infant 'found under a bumper' and seven additional cases that were not related to $\mathrm{CO}_{2} \mathrm{RB}$ (choking, strangulation and fall).
$\mathrm{CO}_{2} \mathrm{RB}$ has been studied in human volunteers (as opposed to experimental surrogates) in controlled settings. Hunt ${ }^{7}$ studied 46 infants (2.6 \pm 0.3 months) who were clinically diagnosed as having a near-miss (N-M) SIDS event and 21 control subjects (2.1 \pm 0.4 months) exposed to $5 \% \mathrm{CO}_{2} /$ normoxic breathing. The definition of N-M SIDS included children with one or more observed episodes of sleep aponea associated with marked pallor or cyanosis and requiring at least minimal stimulation. Control subjects were asymptomatic for sleep aponea. Of note, the authors found that infants with a clinical N-M SIDS history and diminished ventilator response slopes have as a group a concomitant abnormality in arousal (as defined by absence of agitation, eye opening or crying). It is difficult to compare these findings with the data presented herein, as nasal end-tidal partial pressure $\mathrm{CO}_{2}$ was reported by Hunt, whereas we measured percent $\mathrm{CO}_{2}$ in the lung, and the infant respiratory rate and volume was not controlled by Hunt, whereas our ARS rate and volume remained constant. However, Hunt's finding that diminished arousal was found in infants exposed to elevated $\mathrm{CO}_{2}$ levels supports our use of $\mathrm{CO}_{2} \mathrm{RB}$ as a metric for impaired respiration.

Though the study of rebreathing in CBs is limited to the data presented herein, there is enough similarity to rebreathing with crib mattresses that the methods and data from crib mattress rebreathing experiments can be used as basis for the current study. Most notably, Kemp et $a l^{4}$ measured $\mathrm{CO}_{2} \mathrm{RB}$ and mattress softness. $\mathrm{CO}_{2} \mathrm{RB}$ was assessed using a manikin with $\mathrm{CO}_{2}$ measurement capability, with the manikin prone on the mattress. The manikin head was weighted to physiological range. Mattress softness was measured by estimating the contact area between the face and manikin. Of note, the authors found a correlation between softness and $\mathrm{CO}_{2} \mathrm{RB}$. Similarly, Kanetake and colleagues ${ }^{22}$ developed a spherical head-form that accurately and repeatably assessed softness via measurement of contact area. Using a $\mathrm{CO}_{2} \mathrm{RB}$ manikin, the authors concluded that it was difficult to estimate the rebreathing potential of the bedding on the basis of its softness. Based on these studies and the aforementioned clinical studies of infant response to $\mathrm{CO}_{2} \mathrm{RB}$, we theorise that two conditions are necessary for storage and rebreathing of exhaled gases in bedding:

1. An adequate seal is made around the mouth and nose such that exhaled gas is directed into, and gas can be inhaled from, the storage medium (the CB, ML or ALT).

2. The storage medium has sufficient thickness and density and insufficient permeability to make previously exhaled gas available for inhalation.

\section{Limitations}

Our research is subject to certain limitations. First, the mechanical compliance (stiffness) of the ARS face has not been shown to have fidelity to the human infant, nor has the variability in human facial anthropometry been examined; both of these factors may influence the 
interaction between the face and the sample. Second, the ARS has not been validated to show that the $\mathrm{CO}_{2}$ measurements correspond with similar measurements in human infants. To mitigate these two limitations, we have used the ARS to compare the performance of various samples and with other sleeping conditions (blankets, pacifiers and stuffed animals); without additional research, none of the $\mathrm{CO}_{2} \mathrm{RB}$ values reported herein should be interpreted as that which would be expected in a human infant. Further research is needed to validate the ARS measurements against human infants. Finally, our ARS measured $\mathrm{CO}_{2}$ concentration in the lung, not in the blood. That said, we note that end-tidal $\mathrm{CO}_{2}$ has been shown to be correlated with arterial blood $\mathrm{CO}_{2}$ measurements in infants with respiratory distress, ${ }^{26}$ and thus we feel our $\mathrm{CO}_{2}$ measurements are reasonable estimate of relative hypercarbia.

Acknowledgements The authors gratefully acknowledge the contributions of $R$ T Cimini of Bureau Veritas for conduct of the permeability tests, Matthew Howsare (Mintz Levin PC) formerly of the Consumer Product Safety Commission and Susan Klobuchar and Steve Marton of BreathableBaby LLC for insight and guidance on background and study design.

Contributors MRM and ML designed and conducted all experiments. ML was primarily responsible for design and fabrication of the experimental apparatus. MRM was primarily responsible for data analysis and writing the manuscript, with editing by ML.

Funding This research was supported by BreathableBaby, LLC, which provided salary support for study design, data analysis and manuscript preparation, and the costs of laboratory testing. At the time of project inception and before data collection began, the sponsors and the authors decided to submit the data for publication in the peer-reviewed literature.

Competing interests The authors report personal fees from BreathableBaby, LLC, during the conduct of the study.

Patient consent for publication Not required.

Provenance and peer review Not commissioned; externally peer reviewed.

Data sharing statement Data from figures 3 and 4 are available in the online materials.

Open access This is an open access article distributed in accordance with the Creative Commons Attribution Non Commercial (CC BY-NC 4.0) license, which permits others to distribute, remix, adapt, build upon this work non-commercially, and license their derivative works on different terms, provided the original work is properly cited, appropriate credit is given, any changes made indicated, and the use is non-commercial. See: http://creativecommons.org/licenses/by-nc/4.0/.

\section{REFERENCES}

1. Task Force on Sudden Infant Death Syndrome. SIDS and other sleep-related infant deaths: updated 2016 recommendations for a safe infant sleeping environment. Pediatrics 2016;138:e20162938.

2. Scheers NJ, Woodard DW, Thach BT. Crib bumpers continue to cause infant deaths: a need for a new preventive approach. $J$ Pediatr 2016;169:93-7.
3. Carleton JN, Donoghue AM, Porter WK. Mechanical model testing of rebreathing potential in infant bedding materials. Arch Dis Child 1998;78:323-8.

4. Kemp JS, Livne M, White DK, et al. Softness and potential to cause rebreathing: differences in bedding used by infants at high and low risk for sudden infant death syndrome. J Pediatr 1998;132:234-9.

5. Mosko S, Richard C, McKenna J, et al. Maternal proximity and infant $\mathrm{CO} 2$ environment during bedsharing and possible implications for SIDS research. Am J Phys Anthropol 1997;103:315-28.

6. Chiodini BA, Thach BT. Impaired ventilation in infants sleeping facedown: potential significance for sudden infant death syndrome. J Pediatr 1993:123:686-92.

7. Hunt CE. Abnormal hypercarbic and hypoxic sleep arousal responses in near-miss SIDS infants. Pediatr Res 1981;15:1462-4.

8. Corbyn JA. Sudden infant death due to carbon dioxide and other pollutant accumulation at the face of a sleeping baby. Med Hypotheses 1993;41:483-94.

9. Patel AL, Harris K, Thach BT. Inspired $\mathrm{CO} 2$ and $\mathrm{O} 2$ in sleeping infants rebreathing from bedding: relevance for sudden infant death syndrome. J Appl Physiol 2001;91:2537-45.

10. Leshner M. Forensic engineering evaluation of $\mathrm{CO} 2$ re-breathing in infant bedding materials. $J$ Nat Academy of Forensic Engineers 2012;XXIX:23-9.

11. Thach BT, Rutherford GW, Harris K. Deaths and injuries attributed to infant crib bumper pads. J Pediatr 2007;151:271-4.

12. Snyder RG, Spencer ML, Owings CL, et al. Physical characteristics of children as related to death and injury for consumer product safety design. Highway Safety Research Institute: Ann Arbor, Michigan, 1975.

13. Loyd AM, Nightingale R, Bass CR, et al. Pediatric head contours and inertial properties for ATD design. Stapp Car Crash J 2010;54:167-96.

14. Malcolm G, Cohen G, Henderson-Smart D. Carbon dioxide concentrations in the environment of sleeping infants. J Paediatr Child Health 1994;30:45-9.

15. Sakai J, Takahashi S, Funayama M. Gas dispersal potential of infant bedding of sudden death cases. (I): $\mathrm{CO} 2$ accumulation around the face of infant mannequin model. Leg Med 2009;11:S404-5.

16. Kleemann WJ, Schlaud M, Fieguth A, et al. Body and head position, covering of the head by bedding and risk of sudden infant death (SID). Int J Legal Med 1998;112:22-6.

17. Blair PS, Mitchell EA, Heckstall-Smith EM, et al. Head covering - a major modifiable risk factor for sudden infant death syndrome: a systematic review. Arch Dis Child 2008;93:778-83.

18. Gaw CE, Chounthirath T, Midgett J, et al. Types of objects in the sleep environment associated with infant suffocation and strangulation. Acad Pediatr 2017;17:893-901.

19. ASTM. Standard test method for air permeability of textile fabrics. designation: 1737 - 04. West Conshohocken, PA United States, 2012.

20. Filiano JJ, Kinney HC. A perspective on neuropathologic findings in victims of the sudden infant death syndrome: the triple-risk model. Biol Neonate 1994;65:194-7.

21. Moon RY, Horne RSC, Hauck FR. Sudden infant death syndrome. The Lancet 2007:370:1578-87.

22. Kanetake J, Aoki Y, Funayama M. Evaluation of rebreathing potential on bedding for infant use. Pediatr Int 2003;45:284-9.

23. Shapiro-Mendoza CK, Camperlengo L, Ludvigsen R, et al. Classification system for the sudden unexpected infant death case registry and its application. Pediatrics 2014;134:e210-9.

24. Moon RY. SIDS and other sleep-related infant deaths: evidence base for 2016 updated recommendations for a safe infant sleeping environment. Pediatrics 2016;138:e20162940.

25. Centers for Disease Control. Breakdown of sudden unexpected infant death by cause. 2015 https://www.cdc.gov/sids/data.htm.

26. Moses JM, Alexander JL, Agus MS. The correlation and level of agreement between end-tidal and blood gas $\mathrm{pCO} 2$ in children with respiratory distress: a retrospective analysis. BMC Pediatr 2009;9:20. 